\title{
Natural seabed gas leakage -- variability imposed by tidal cycles
}

\author{
Jianghui Li, Paul R. White, Ben Roche ${ }^{\dagger}$, Jonathan M. Bull ${ }^{\dagger}$, John W. Davis ${ }^{\dagger}$, Timothy G. Leighton, \\ Michele Deponte ${ }^{\ddagger}$, Emiliano Gordini ${ }^{\ddagger}$, and Diego Cotterle $\ddagger$ \\ Institute of Sound and Vibration Research, University of Southampton SO17 1BJ, U.K. \\ ${ }^{\dagger}$ Ocean and Earth Science, University of Southampton, National Oceanography Centre, Southampton SO14 3ZH, U.K. \\ ${ }_{\ddagger}^{\ddagger}$ National Institute of Oceanography and Applied Geophysics, Borgo Grotta Gigante 42/c-34010-Sgonico(TS), Italy \\ E-mail: J.Li@ soton.ac.uk
}

\begin{abstract}
The likelihood of leakage from sub-seabed Carbon Capture and Storage (CCS) sites has been debated since geological storage was proposed as an effective option to remove greenhouse gas emissions from the climate system. Within the marine environment, passive acoustics has been presented as a feasible way for detecting and quantifying any such leakage. When determining estimates of gas escape across the seabed, the influence of dynamic environments, introducing natural variations in seepage rates must be considered, including tidal cycles. Panarea, Sicily, is the location of a series of natural marine $\mathrm{CO}_{2}$ gas seeps and provides an excellent test bed to investigate variations of natural seabed gas leakage across a tidal cycle. A multivariate statistical approach was used to recognize the relationship when gas leakage is dominated by natural forcing. We show that the tidal height correlates negatively with the bubble sound power spectral density, the gas flux, and the bubble size. The strength of the correlation can vary significantly for different investigated time periods of observation, showing sensitivity of tidal influence. Our results corroborate evidence that natural migration of $\mathrm{CO}_{2}$ through the seabed is moderated by tidal cycles.
\end{abstract}

Index Terms-Carbon Capture and Storage (CCS), gas leakage, tide, passive acoustics, greenhouse gas

\section{INTRODUCTION}

In recent years, offshore Carbon Capture and Storage (CCS) has been proposed as an effective option for reducing greenhouse gas emission into the atmosphere [1]-[4]. However, the possibility of leakage from a CCS site is an ongoing concern, and multiple strategies for monitoring and quantification of such leaks have been presented [5]-[9]. Among these strategies, passive acoustic monitoring has been presented as one of the feasible techniques [6], [10]-[12].

Research on excess $\mathrm{CO}_{2}$ in marine systems is frequently based on laboratory experiments and studies of natural $\mathrm{CO}_{2}$ seeps [13]. Ideally, the area selected should have an element of tidal flushing, distributing $\mathrm{CO}_{2}$ enriched sea water to facilitate investigations into techniques for tracing $\mathrm{CO}_{2}$ leaks over wide area, but not so great a flushing rate that there would be no build-up of $\mathrm{CO}_{2}$ concentrations in the area during the experiments. Controlled $\mathrm{CO}_{2}$ release in the marine environment [11] has shown that seepage is tidally moderated.

Panarea, as shown in Fig. 1, is a small Aeolian island in the southern Tyrrhenian Sea, northeast of Sicily [14]-[19]. The island and its associated islets are the subaerial expression

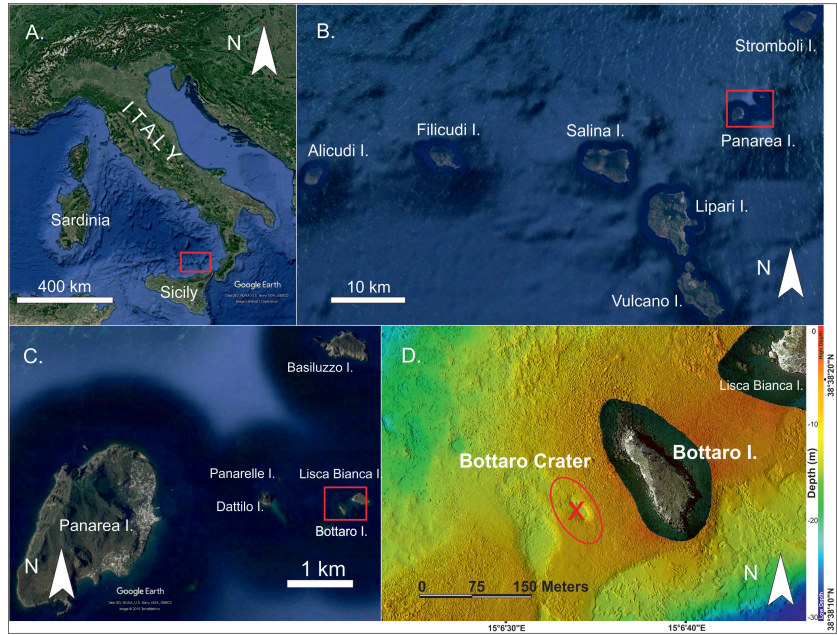

Fig. 1. Map of Panarea island and the surrounding islets. The deployment site (marked as a red star) is located northeast edge of the isolated islet Lisca Bianca along fracture $\left(38^{\circ} 38^{\prime} 25^{\prime \prime} \mathrm{N}, 15^{\circ} 06^{\prime} 56^{\prime \prime} \mathrm{E}\right)$. The seep site depth is $12.5 \mathrm{~m}$ below water surface. The sea state was primarily 2 .

of a large submarine stratovolcano, originally formed by the subduction of the African continental plate below the Eurasian plate [16], [20], [21]. While there has been no evidence of volcanic activity on the island over the last 8000 years [22] the underlying silicic magma chamber is still present and has established a shallow hydrothermal system [23] resulting in dozens of natural $\mathrm{CO}_{2}$ seeps in the area.

Analysis of these seep have shown the gas content to be relatively stable composed of $98 \% \mathrm{CO}_{2}, 1.7 \% \mathrm{H}_{2} \mathrm{~S}$ and $0.3 \%$ other trace gases $\left(\mathrm{N}_{2}, \mathrm{He}, \mathrm{H}_{2}, \mathrm{CH}_{4}\right)$ [17], [24]-[26], though the physical rate of gas flux can vary greatly from one seep to the next. This variety of natural $\mathrm{CO}_{2}$-rich gas seeps make Panarea an excellent site to study variations in natural gas leakage in a dynamic marine environment. Indeed, gas leakage in offshore Panarea has been studied in depth since the 1980s [27], [28], with over 80 release sites mapped throughout the surveyed area [16]. There has even been continuous passive acoustic monitoring of bubble flux [29], focusing on the sensitivity of tidal activity on seabed gas leakage over different length of recording, though this has not yet been statistically investigated. 
In this paper, we investigate the influence and acoustic sensitivity of tidal activity on natural sub-seabed $\mathrm{CO}_{2}$ leakage over different time lengths of observation. We attempt to address the following questions: (1) how much does the tidal variation affect the power spectral density (PSD) and the standard deviation of the PSD; (2) how does the tidal cycle moderate gas flux and bubble size variation?

The paper is organized as follows. Sections II describes the methods. Section III gives the correlation relationship between measured and inverted values. Section IV summarizes the paper with conclusions and discussion.

\section{Methods}

In this section, we describe methods of deployment, signal processing, passive inversion, and correlation.

\section{A. Deployment}

This study was centred in Bottaro Crater, a $1 \mathrm{~m}$ deep depression in the seabed formed by a gas eruption in 2002, $3.3 \mathrm{~km}$ to the east of Panarea (Fig. 1), which is in water depth of around $12 \mathrm{~m}$ depending on tidal height. $\mathrm{CO}_{2}$-rich gas bubbles are continuously escaping from the body of the crater with more focused seeps located along the perimeter. A video survey prior to deployment was used to plan equipment deployment and provide an alternative estimate of bubble size and gas flux for later comparison.

A calibrated 'RS Orca' hydrophone was deployed in the center of the crater, $2 \mathrm{~m}$ away from the closest continuously active seep, to record the acoustic signature being emitted by gas bubbles escaping into the seabed. The hydrophone was calibrated with receive sensitivity of $-164.5 \mathrm{~dB}$ re: $1 \mathrm{~V} / \mu \mathrm{Pa}$, possessing a gain of $15 \mathrm{~dB}$, and a sampling frequency of $96 \mathrm{kHz}$. The recording started at 13:45 on 14th May 2018 and lasted for 17 hours until 06:53 on 15th May 2018.

Tidal information and relevant weather data were obtained at 10-min interval. Recorded data of tidal oscillations was used for multivariate data analysis. The data set is applied to identify dependencies between the variables, i.e., tidal level, PSD parameters, and gas leakage quantifications.

\section{B. Signal processing}

The acoustic signature recorded from the channel is processed with 10-s observation windows. Relative statistics include PSD and standard deviation of the PSD. Based on the recorded data, a robust Least Square (RLS) regression model was used to identify parameters, which contributed significantly to tidal variations.

1) Power spectral density (PSD): A general quantitative description of the seafloor noise can be provided by the analysis of PSD. The noise PSD is estimated using the Welch's PSD estimate technique [30]. It works on the chosen noise period with $f_{s} / 2$ points overlapping, to reduce the variance of the periodogram, breaks the time series into segments, and returns one-sided Welch PSD estimates [30]:

$$
\left[\mathrm{PSD}_{k}\right]=\operatorname{pwelch}\left(x_{k}(i)\right), k=1,2, \ldots, K,
$$

where the 'pwelch' represents the Welch's technique [30], a hamming window of equal length $f_{s}$ is used, and the NFFT size is chosen as $f_{s} / 2$. The $\mathrm{PSD}_{k}\left[\mathrm{~dB}\right.$ re $\mu \mathrm{Pa}^{2} / \mathrm{Hz}$ ] for the $k$ th fragment is finally computed with considering the gain and frequency dependent sensitivity of the hydrophone known from design specification. Thus, the estimate of the noise PSD would be the average at each time fragment.

2) PSD standard deviation: To find the acoustic sensitivity of the seafloor noise and the power variance of the signal as a function of frequency, the PSD standard deviation $\rho$ is evaluated for each $2 \min (J=12$ fragments). The $m$ th $\min$ $\rho_{m}$ is computed as:

$$
\rho_{m}=\sqrt{\frac{1}{J-1} \sum_{j=1}^{J}\left|\operatorname{PSD}_{m}(j)-\mu_{m}\right|}, j=1,2, \ldots, J,
$$

where $\mu_{m}$ is the mean of $\operatorname{PSD}_{m}(j)$.

3) Smoothing technique: In practical, because the ambient noise (e.g., biological noise) has taken up a large portion of the acoustic recording, we firstly need to identify outliers and assign lower weight or zeros weight to these outliers. Thus, we process the collected tidal data and the estimated gas flux using a smoothing technique based on robust locally weighted regression presented by Cleveland [31]. The technique combines local fitting of polynomials [32] and robust estimation by adaptation of iterated weighted least squares [33], [34], which guards against deviant points distorting the smoothed points [31], i.e., it gives the most weight to the data points nearest the point of estimation and the least weight to the data points that are furthest away. It is preferable that the smoothed line is insensitive to these kinds of deviations. To compare and identify agreements between the time-variations of tides and the estimated gas flux, we have been setting different span (e.g., a certain percent of the whole data) for the moving average filter in the regression.

\section{Passive inversion model}

Acoustic inversion is used to quantify fluxes of gaseous $\mathrm{CO}_{2}$ and determine bubble size and to assess associated impacts from ambient, e.g., tide [35]. For inversion of the gas flux from the bubble stream, we identify the dominant frequency range, $\left[f_{\min }, f_{\max }\right]$ over which the sound of the bubbles is evident above the ambient noise field. The radii of the bubbles whose resonant frequencies correspond to $f_{\min }$ and $f_{\max }$ are identified and are $R_{\max }$ and $R_{\min }$ respectively [36]. Then we create a bin vector of the radii $R_{0}$ with each bin equaling to $\left(R_{\max }-R_{\min }\right) / M$, where $M$ is the number of bins. For each bin, we integrate the measured power spectral density across the bin [35].

Based on the computed acoustic pressure, we estimate the bubble size distribution and population from the recorded passive acoustic data using the passive acoustic inversion (see details in [35]). Thus, the probability density function (PDF) of bubble equilibrium radius $p_{\mathrm{b}}^{R_{0}}$ as well as the number of bubbles for each size are obtained, and the gas flow rate $F$ $[\mathrm{L} / \mathrm{min}]$ is then computed. Due to the short distance from the 
hydrophone to the seep site $(2 \mathrm{~m})$, here we have not consider underwater multipath propagation [12], [37]-[40], e.g., sea surface reflection, and apply the spherical spreading of the bubble sound in the acoustic channel.

\section{Correlation coefficient}

Corrections between these values, i.e., tidal level, sound PSD, standard deviation of PSD, inverted seabed gas flux and bubble size, can vary over different length of recording. Here we present the cross-correlation of these values based on the field data. To show the strength of linear relationship between two variables, the Pearson correlation coefficient [38], [41] is used as

$$
\xi=\frac{\sum_{k=1}^{K}\left(\varphi_{1}(k)-\bar{\varphi}_{1}\right)\left(\varphi_{2}(k)-\bar{\varphi}_{2}\right)}{\sqrt{\varepsilon_{1}^{2}} \sqrt{\varepsilon_{2}^{2}}},
$$

where

$$
\varepsilon_{1}^{2}=\sum_{k=1}^{K}\left(\varphi_{1}(k)-\bar{\varphi}_{1}\right)^{2}
$$

and

$$
\varepsilon_{2}^{2}=\sum_{k=1}^{K}\left(\varphi_{2}(k)-\bar{\varphi}_{2}\right)^{2},
$$

are covariance of the variables, $\varphi_{1}(k)$ and $\varphi_{2}(k)$ are the two variables, $\bar{\varphi}_{1}$ and $\bar{\varphi}_{2}$ are mean values of the two variables, respectively. Values between 0 and 0.3 (0 and -0.3) indicate a weak positive (negative) linear relationship via a shaky linear rule; values between 0.3 and 0.7 (-0.3 and -0.7) indicate a moderate positive (negative) linear relationship via a fuzzyfirm linear rule; and values between 0.7 and 1.0 (-0.7 and -1.0) indicate a strong positive (negative) linear relationship via a firm linear rule [41].

\section{RESULTS}

Fig. 2 shows the acoustic spectrum, tidal level, sound PSD, standard deviation of PSD, the inverted seabed gas flux and bubble mean radius. The tidal data covers 1.5 cycles. It can be observed that as the tidal height changes, the level of the PSD, hydrophone-determined gas flux and bubble size gently changes in an opposite direction. A strong correlation between peaks in gas flux and bubble size and low tide was observed in most cases, but some of them did not show correlation due to the surrounding and occasional noise, such as at around 19:30 and 21:45 on 14th May, 2018. Moreover, it is difficult to see tidal correlation in time period to gas flux and bubble radius only from this figure, thus we seek help from cross-correlation.

The cross-correlation results are shown in Fig. 3, from which the tidal dependency can be observed. In short period corresponding to small smooth span $<0.1 \%$, the tidal level is modest positively correlated with the PSD standard deviation (Std), modest negatively correlated with the PSD, and weak correlated with the gas flux and bubble radius. While in the long period corresponding to large smooth span $>10 \%$, the tidal level is strong positively correlated with the PSD Std, and strong negatively correlated with the PSD, the gas flux and bubble radius. The PSD is modest positively correlated with its Std in short period while strong negatively correlated with its Std in long period. As the smooth span increases, the positive correlation between gas flux and bubble radius becomes stronger. The short period correlation shows instant changes, while the long period correlation shows the influence of tidal cycles on $\mathrm{CO}_{2}$ gas seepage. The PSD value and the standard deviation of it possess negative correlation in short period (instant agitation) and positive correlation in long period (daily tidal cycle). The size of the leakage bubbles have stronger negative correlation with the tide than with the seabed gas flux.

Fig. 4 shows the seabed gas seep related variables correlating with tidal circulation of $\sim 12$ hours, showing a negative correlation between tidal level and PSD, gas flux, as well as bubble size. It is shown that in dynamic water areas like offshore Panarea, natural variability is comparable in its levels of gas seep variation with the effects of tidal variation. Natural forcing, such as tide, may be a strong factor in the gas seepage from the seabed. In general, the circulation offshore Panarea is tidally driven and the influence of tidal circulation was significant on all the measured seep variables.

\section{CONCLUSIONS AND DISCUSSION}

Multivariate analysis of tidal and acoustic data using crosscorrelation is an efficient tool in identifying correlations for different time periods of observation. During the acoustic recording, the strongest positive dependence was found between gas flow rate and bubble size, and the strongest negative correlation was found between high tidal height and small bubble size (due to greater hydrostatic pressure reducing bubble size). We show that the tidal activity correlates significantly with the gas seep related sound PSD, the standard deviation of PSD, the inverted seabed gas flux and bubble radius. Our results corroborate evidence that natural migration of $\mathrm{CO}_{2}$ through the seabed is moderated by tidal activities with strong negative correlation.

Gaseous $\mathrm{CO}_{2}$ flow rates estimated from acoustic inversion varied significantly with tidally induced changed in hydrostatic pressure. Impact is indicated not by change per second, but by deviations from well-established normal tidal cycles. Intermittently the high gas flux in the water column was advected increased owing to tidal circulation, inducing bubble sound strength change. Bubble streams, when present, are easily recorded, but we observed that these are sensitive to hydrostatic pressure and may represent a fraction of released $\mathrm{CO}_{2}$. While as only 18 hours data were observed and analysed here, the results on the gas leakage variability due to tidal cycles are limited. Longer measurement, e.g., more than tidal cycles, could be useful to provide more information on the correlation between environmental parameters (e.g., tidal level) and measured acoustic data characteristics.

\section{ACKNOWLEDGEMENT}

Funding was provided by the European Unions Horizon 2020 research and innovation programme under the grant agreement number 654462 (STEMM-CCS). We thank the 


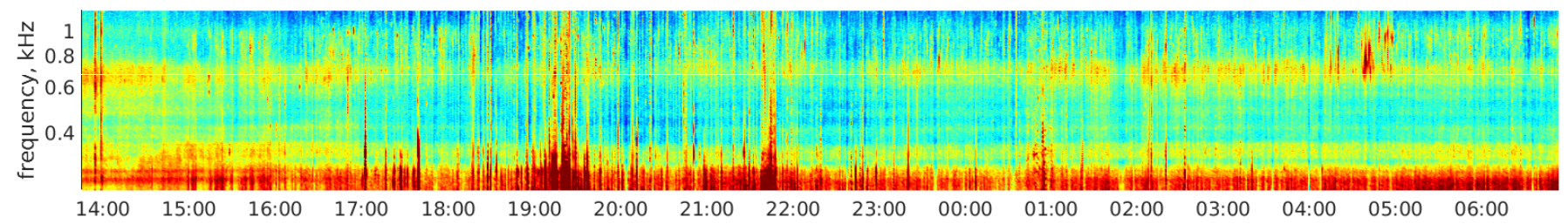

(a) power spectral density (PSD)

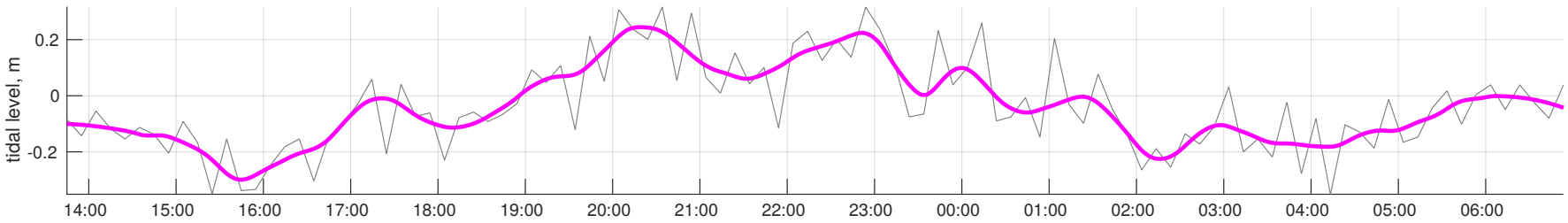

(b) tide over average level (10\% span smoothed - purple line)

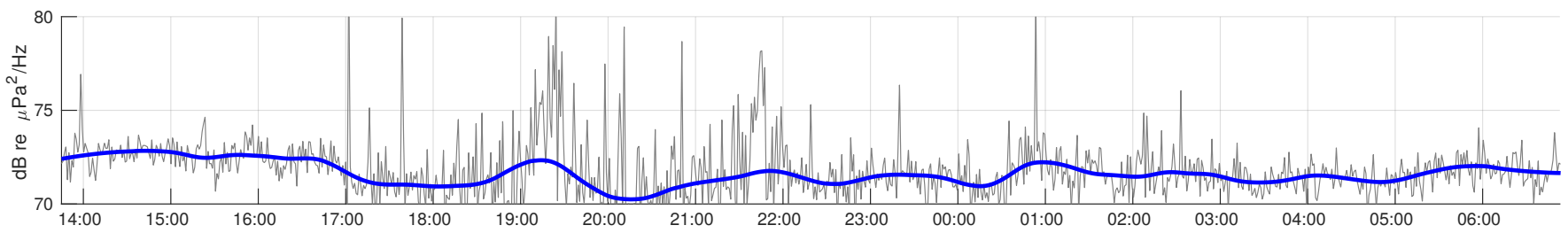

(c) PSD at $700 \mathrm{~Hz}(10 \%$ span smoothed - blue line)

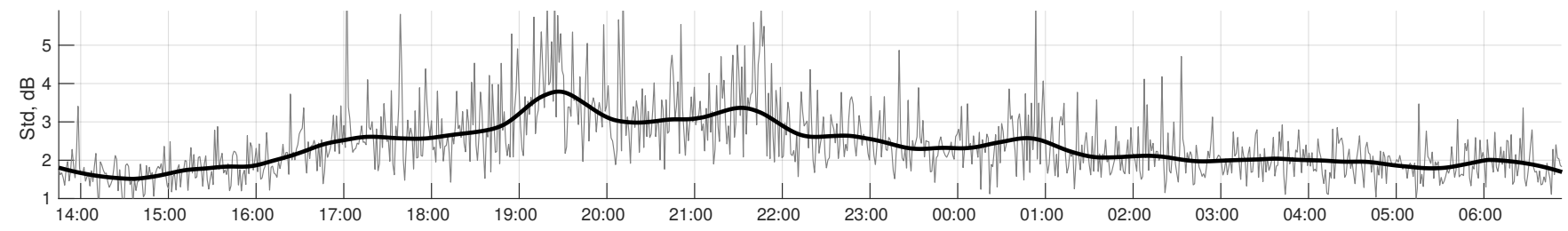

(d) standard deviation (Std) of PSD at $700 \mathrm{~Hz}$ (10\% span smoothed - black line)

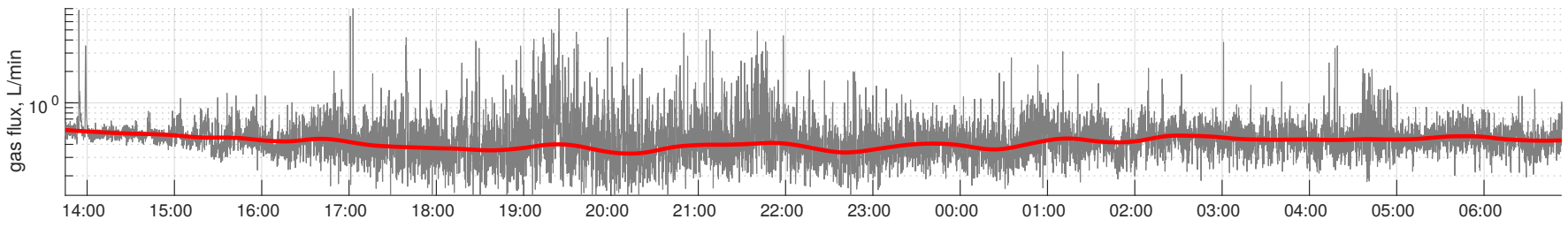

(e) estimate of gas flux (10\% span smoothed - red line)

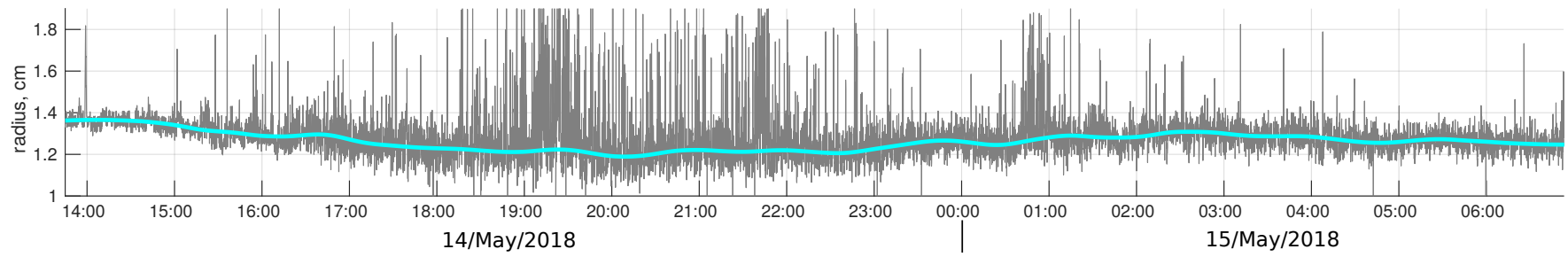

(f) bubble mean radius (10\% span smoothed - cyan line)

Fig. 2. Acoustic sound power spectral density (PSD), standard deviation (Std) of PSD, hydrophone-determined seabed flux and bubble size variations in the water column over 17 hours (approximately 1.5 tidal cycles). Seabed gas flux and bubble mean radius inversely correlate with the tidal cycle, with low gas flux and small bubble size at high tide. (a) PSD; (b) tide over average level; (c) PSD at $700 \mathrm{~Hz}$; (d) standard deviation (Std) of PSD at $700 \mathrm{~Hz}$; (e) estimate of gas flux; (f) bubble mean radius at the seabed from inversion of hydrophone data with 50th percentile of confidence interval. 


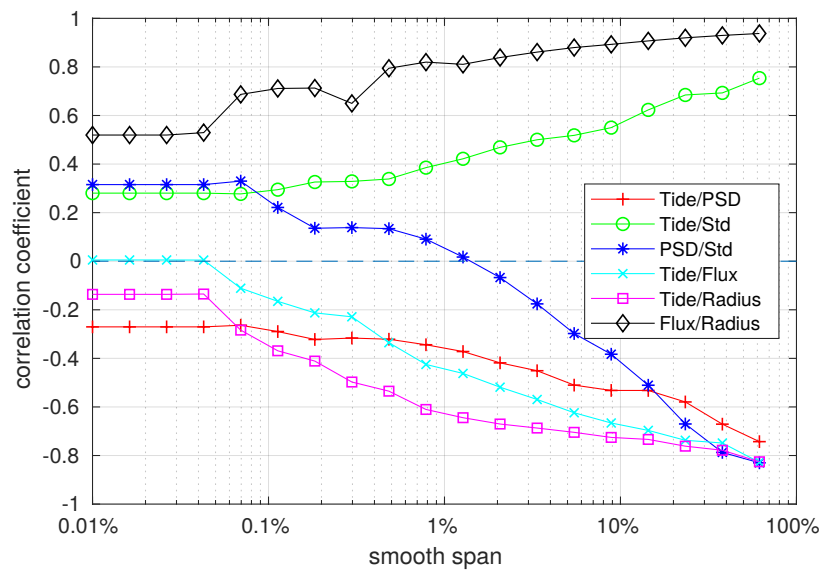

Fig. 3. Multivariate analysis of the collected data: correlation coefficient between different variable pairs. Negative points and distanced far away from 0 indicate strong negative correlation between the variables. Points that are closer to 0 have weaker influence on the model.
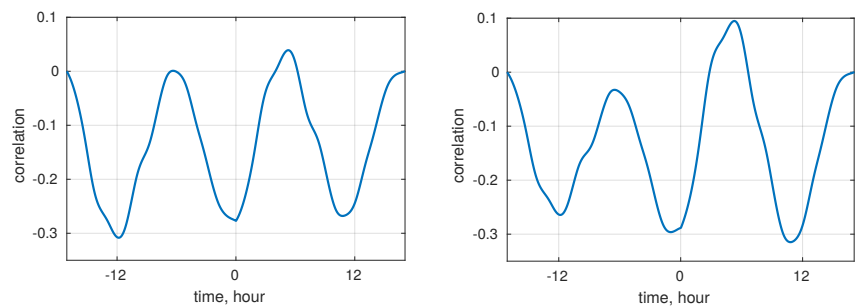

(a) tide vs. power spectral density (b) tide vs. standard deviation (Std) of (PSD) PSD

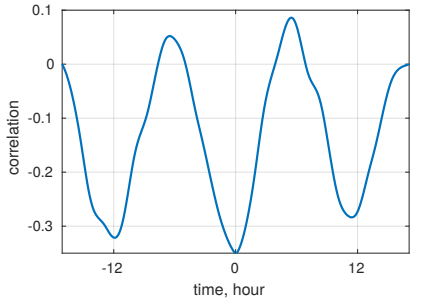

(c) tide vs. gas flux

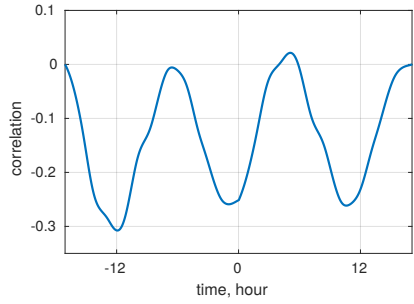

(d) tide vs. bubble mean radii
Fig. 4. Cross-correlation between the $10 \%$ span smoothed tide from the Panarea seepage site for the 17-hour observation period with (a) the power spectral density (PSD); (b) the standard deviation (Std) of PSD; (c) the calculated gas flux; and (d) the bubble mean size recorded.

scientific divers Andrea Fogliozzi and Martina Gaglioti for their professional and tireless work.

\section{REFERENCES}

[1] E. Rastelli, C. Corinaldesi, A. Dell'Anno, T. Amaro, A. M. Queirós, S. Widdicombe, and R. Danovaro, "Impact of $\mathrm{CO}_{2}$ leakage from subseabed carbon dioxide capture and storage (CCS) reservoirs on benthic virus-prokaryote interactions and functions," Frontiers in microbiology, vol. 6 , p. $935,2015$.

[2] K. Shitashima, Y. Maeda, and T. Ohsumi, "Development of detection and monitoring techniques of $\mathrm{CO}_{2}$ leakage from seafloor in sub-seabed $\mathrm{CO}_{2}$ storage," Applied geochemistry, vol. 30, pp. 114-124, 2013.

[3] A. Carroll, R. Przeslawski, L. Radke, J. Black, K. Picard, J. Moreau, R. Haese, and S. Nichol, "Environmental considerations for subseabed geological storage of $\mathrm{CO}_{2}$ : A review," Continental Shelf Research, vol. 83, pp. 116-128, 2014
[4] A. B. Weeks, "Subseabed carbon dioxide sequestration as a climate mitigation option for the Eastern United States: A preliminary assessment of technology and law," Ocean \& Coastal LJ, vol. 12, p. 245, 2006.

[5] K. Shitashima, Y. Maeda, and A. Sakamoto, "Detection and monitoring of leaked $\mathrm{CO}_{2}$ through sediment, water column and atmosphere in a sub-seabed CCS experiment," International Journal of Greenhouse Gas Control, vol. 38, pp. 135-142, 2015.

[6] P. Taylor, H. Stahl, M. E. Vardy, J. M. Bull, M. Akhurst, C. Hauton, R. H. James, A. Lichtschlag, D. Long, D. Aleynik et al., "A novel sub-seabed $\mathrm{CO}_{2}$ release experiment informing monitoring and impact assessment for geological carbon storage," International Journal of Greenhouse Gas Control, vol. 38, pp. 3-17, 2015.

[7] D. Atamanchuk, A. Tengberg, D. Aleynik, P. Fietzek, K. Shitashima, A. Lichtschlag, P. O. Hall, and H. Stahl, "Detection of $\mathrm{CO}_{2}$ leakage from a simulated sub-seabed storage site using three different types of $\mathrm{pCO}_{2}$ sensors," International Journal of Greenhouse Gas Control, vol. 38, pp. $121-134,2015$.

[8] Y. Maeda, K. Shitashima, and A. Sakamoto, "Mapping observations using AUV and numerical simulations of leaked $\mathrm{CO}_{2}$ diffusion in subseabed $\mathrm{CO}_{2}$ release experiment at Ardmucknish Bay," International Journal of Greenhouse Gas Control, vol. 38, pp. 143-152, 2015.

[9] K. Shitashima, Y. Maeda, and T. Ohsumi, "Strategies for detection and monitoring of $\mathrm{CO}_{2}$ leakage in sub-seabed CCS," Energy Procedia, vol. 37, pp. 4283-4290, 2013.

[10] J. Blackford, J. M. Bull, M. Cevatoglu, D. Connelly, C. Hauton, R. H. James, A. Lichtschlag, H. Stahl, S. Widdicombe, and I. C. Wright, "Marine baseline and monitoring strategies for carbon dioxide capture and storage (CCS)," International Journal of Greenhouse Gas Control, vol. 38, pp. 221-229, 2015.

[11] J. Blackford, H. Stahl, J. M. Bull, B. J. Bergès, M. Cevatoglu, A. Lichtschlag, D. Connelly, R. H. James, J. Kita, D. Long et al., "Detection and impacts of leakage from sub-seafloor deep geological carbon dioxide storage," Nature climate change, vol. 4, no. 11, p. 1011 , 2014.

[12] J. Li, P. R. White, J. M. Bull, and T. G. Leighton, "A noise impact assessment model for passive acoustic measurements of seabed gas fluxes," Ocean Engineering, vol. 183, no. 1, pp. 294-304, 2019.

[13] G. Caramanna, N. Voltattorni, and M. M. Maroto-Valer, "Is Panarea Island (Italy) a valid and cost-effective natural laboratory for the development of detection and monitoring techniques for submarine $\mathrm{CO}_{2}$ seepage?" Greenhouse Gases: Science and Technology, vol. 1, no. 3, pp. 200-210, 2011

[14] J. Lupton, C. de Ronde, M. Sprovieri, E. T. Baker, P. P. Bruno, F. Italiano, S. Walker, K. Faure, M. Leybourne, K. Britten et al., "Active hydrothermal discharge on the submarine Aeolian Arc," Journal of Geophysical Research: Solid Earth, vol. 116, no. B2, 2011.

[15] S. Graziani, S. E. Beaubien, S. Bigi, and S. Lombardi, "Spatial and temporal $\mathrm{pCO}_{2}$ marine monitoring near Panarea Island (Italy) using multiple low-cost GasPro sensors," Environmental science \& technology, vol. 48, no. 20, pp. 12 126-12 133, 2014.

[16] M. Schmidt, P. Linke, S. Sommer, D. Esser, and S. Cherednichenko, "Natural $\mathrm{CO}_{2}$ seeps offshore Panarea: A test site for subsea $\mathrm{CO}_{2}$ leak detection technology," Marine Technology Society Journal, vol. 49, no. 1, pp. 19-30, 2015.

[17] G. Caramanna, P. Fietzek, and M. Maroto-Valer, "Monitoring techniques of a natural analogue for sub-seabed $\mathrm{CO}_{2}$ leakages," Energy Procedia, vol. 4, pp. 3262-3268, 2011.

[18] G. Caramanna, Y. Wei, M. M. Maroto-Valer, P. Nathanail, and M. Steven, "Laboratory experiments and field study for the detection and monitoring of potential seepage from $\mathrm{CO}_{2}$ storage sites," Applied geochemistry, vol. 30, pp. 105-113, 2013.

[19] L. Beccaluva, G. Gabbianelli, F. Lucchini, P. Rossi, and C. Savelli, "Petrology and K/Ar ages of volcanics dredged from the Eolian seamounts: implications for geodynamic evolution of the southern Tyrrhenian basin," Earth and Planetary Science Letters, vol. 74, no. 2-3, pp. 187-208, 1985.

[20] V. M. Dekov and C. Savelli, "Hydrothermal activity in the SE Tyrrhenian Sea: an overview of 30 years of research," Marine Geology, vol. 204, no. 1-2, pp. 161-185, 2004.

[21] A. Esposito, G. Giordano, and M. Anzidei, "The 2002-2003 submarine gas eruption at Panarea volcano (Aeolian Islands, Italy): Volcanology of the seafloor and implications for the hazard scenario," Marine Geology, vol. 227 , no. 1-2, pp. 119-134, 2006. 
[22] F. Lucchi, C. Tranne, N. Calanchi, P. Rossi, and J. Keller, "The stratigraphic role of marine deposits in the geological evolution of the Panarea volcano (Aeolian Islands, Italy)," Journal of the Geological Society, vol. 164, no. 5, pp. 983-996, 2007.

[23] R. E. Price, D. E. LaRowe, F. Italiano, I. Savov, T. Pichler, and J. P. Amend, "Subsurface hydrothermal processes and the bioenergetics of chemolithoautotrophy at the shallow-sea vents off Panarea Island (Italy)," Chemical geology, vol. 407, pp. 21-45, 2015.

[24] S. Aliani, G. Bortoluzzi, G. Caramanna, and F. Raffa, "Seawater dynamics and environmental settings after November 2002 gas eruption off Bottaro (Panarea, Aeolian Islands, Mediterranean Sea)," Continental Shelf Research, vol. 30, no. 12, pp. 1338-1348, 2010.

[25] A. Caracausi, M. Ditta, F. Italiano, M. Longo, P. Nuccio, A. Paonita, and A. Rizzo, "Changes in fluid geochemistry and physico-chemical conditions of geothermal systems caused by magmatic input: The recent abrupt outgassing off the island of Panarea (Aeolian Islands, Italy)," Geochimica et Cosmochimica Acta, vol. 69, no. 12, pp. 3045-3059, 2005.

[26] G. Chiodini, S. Caliro, G. Caramanna, D. Granieri, C. Minopoli, R. Moretti, L. Perotta, and G. Ventura, "Geochemistry of the submarine gaseous emissions of Panarea (Aeolian Islands, Southern Italy) magmatic vs. hydrothermal origin and implications for volcanic surveillance," Pure and applied Geophysics, vol. 163, no. 4, pp. 759-780, 2006.

[27] F. Italiano and P. Nuccio, "Geochemical investigations of submarine volcanic exhalations to the east of Panarea, Aeolian Islands, Italy," Journal of Volcanology and Geothermal Research, vol. 46, no. 1-2, pp. 125-141, 1991.

[28] N. Calanchi, B. Capaccioni, M. Martini, F. Tassi, and L. Valentini ${ }^{\circ}$, "Submarine gas-emission from Panarea Island (Aeolian Archipelago): distribution of inorganic and organic compounds," Acta Vulcanologica, vol. 7, no. 1, pp. 43-48, 1995.

[29] F. Italiano, R. Maugeri, A. Mastrolia, and J. Heinicke, "SMM, a new seafloor monitoring module for real-time data transmission: an application to shallow hydrothermal vents," Procedia Earth and Planetary Science, vol. 4, pp. 93-98, 2011.

[30] P. Welch, "The use of fast Fourier transform for the estimation of power spectra: a method based on time averaging over short, modified periodograms," IEEE Transactions on audio and electroacoustics, vol. 15, no. 2, pp. 70-73, 1967.

[31] W. S. Cleveland, "Robust locally weighted regression and smoothing scatterplots," Journal of the American statistical association, vol. 74, no. 368, pp. 829-836, 1979.

[32] F. R. Macaulay et al., "The smoothing of time series," NBER Books, 1931.

[33] A. E. Beaton and J. W. Tukey, "The fitting of power series, meaning polynomials, illustrated on band-spectroscopic data," Technometrics, vol. 16, no. 2, pp. 147-185, 1974.

[34] D. F. Andrews, "A robust method for multiple linear regression," Technometrics, vol. 16, no. 4, pp. 523-531, 1974.

[35] T. Leighton and P. White, "Quantification of undersea gas leaks from carbon capture and storage facilities, from pipelines and from methane seeps, by their acoustic emissions," Proc. R. Soc. A, p. rspa20110221, 2011.

[36] T. G. Leighton, "The acoustic bubble," ISBN: 0-12-44190-8, 1994.

[37] J. Li, L. Liao, and Y. V. Zakharov, "Space-time cluster combining for UWA communications," in OCEANS 2016-Shanghai. IEEE, 2016, pp. $1-6$.

[38] J. Li, "DOA tracking in time-varying underwater acoustic communication channels," in MTS/IEEE OCEANS 2017-Aberdeen, 2017, pp. 1-9.

[39] J. Li, Y. V. Zakharov, and B. Henson, "Multibranch Autocorrelation Method for Doppler Estimation in Underwater Acoustic Channels," IEEE Journal of Oceanic Engineering, vol. 43, no. 4, pp. 1099 - 1113, 2018.

[40] J. Li and Y. V. Zakharov, "Efficient use of space-time clustering for underwater acoustic communications," IEEE Journal of Oceanic Engineering, vol. 43, no. 1, pp. 173-183, 2018.

[41] J. Benesty, J. Chen, Y. Huang, and I. Cohen, "Pearson correlation coefficient," in Noise reduction in speech processing. Springer, 2009, pp. $1-4$. 